\author{
Paweł DOBRZAŃSKI ${ }^{1}$ \\ Mirosław ŚMIESZEK ${ }^{2}$ \\ Magdalena DOBRZAŃSKA ${ }^{3}$
}

\title{
BICYCLE TRANSPORT WITHIN SELECTED POLISH AND EUROPEAN UNION CITIES
}

\begin{abstract}
Urban transport and its organization is one of the most important areas related to the functioning of the city. Properly organized urban transport should quickly and efficiently meet all transport needs. Transport activities can have negative effects on the urban environment. The most significant are congestion, environmental pollution, and noise. In addition to the negative impact on the city's environment, transport also contributes to the consumption of non-renewable energy sources. For this reason, the idea of sustainable transport has started to play an important role in recent years. This idea provides residents with economically and time-favorable ways of moving while limiting the impact of transport's harmful effects on the environment. Bicycle transport is an important element of sustainable transport; in many cases, it is faster and has zero emissions. The purpose of this article was to present the impact of selected factors such as the size of the city and the degree of economic development on the functioning of bicycle transport in selected cities of the European Union and Poland.
\end{abstract}

Keywords: bicycle transport, sustainable transport, public transport.

\section{INTRODUCTION}

Properly functioning public transport is the basis for the right functioning of the urban organism. The transport needs of urban residents depend on the degree of economic development of the urban area and its size and number of citizens. The functioning urban transport is also responsible for a number of adverse effects for the city and its inhabitants. The most significant harmful effects include congestion, environmental pollution and noise (Śmieszek, 2019). Not all forms of urban transport have the same environmental impact. The most friendly and least burdensome form of urban transport is bicycle transport. Currently, a growing policy is being implemented in an increasing number of cities to promote intra-city cycling (Woods, 2017). Bicycle transport is one of the most common

${ }^{1}$ Paweł Dobrzański, PhD, Eng., Assistant Prof., Rzeszow University of Technology, The Faculty of Management, al. Powstańców Warszawy 12, 35-959 Rzeszow; e-mail: pd@prz.edu.pl (corresponding author). ORCID: 0000-0001-5182-4999.

${ }^{2}$ Mirosław Śmieszek, DSc, PhD, Eng., Associate Prof., Rzeszow University of Technology, The Faculty of Management, al. Powstańców Warszawy 12, 35-959 Rzeszow; e-mail: msmieszk@prz. edu.pl. ORCID: 0000-0002-4508-6309.

${ }^{3}$ Magdalena Dobrzańska, PhD, Eng, Assistant Prof., Rzeszow University of Technology, The Faculty of Management, al. Powstańców Warszawy 12, 35-959 Rzeszow; e-mail: md@ prz.edu.pl. ORCID: 0000-0002-6209-5944. 
ways to eliminate environmental pollution and reduce congestion in the city (Bagloee 2016). Cities to encourage residents to use a bicycle, most often invest in the development of bicycle paths, the construction of rental shops and appropriate street marking (Gutierrez, 2020). City bike systems operate in over 600 cities around the world (Kaltenbrunner, 2010). Cities decide to launch city bike systems for several reasons: to increase cycling, to reduce congestion, to improve air quality, and offerresidents an alternative to urban transport in the form of active mobility. In addition, the city bike has two main advantages compared to other transport projects: implementation costs are relatively low and the duration of the entire project is short. It is possible to plan and implement the system in a very short time, which means that the benefits accrued from the functioning of the system can be obtained much faster than in the case of other urban transport projects (e.g. investments in new buses).

The purpose of this article was to present the impact of selected factors such as the size of the city and the degree of economic development on the functioning of bicycle transport in selected cities of the European Union and Poland. The article presents the advantages and disadvantages of cycling. The activities of selected EU and Polish cities were also presented, aimed at developing bicycle transport.

\section{ADVANTAGES AND DISADVANTAGES OF CYCLING}

Each means of communication has advantages and disadvantages, but there is one that combines especially many advantages - it is bicycle transport. Convenience and comfort can be debatable, but when it comes to economic and ecological indicators, the bike can without any doubt boast about the highest place.

The first advantage is virtually zero operating cost. The highest costs are incurred when purchasing this means of transport. Despite this, they are incomparably lower compared to all others. Additional costs incurred by the bicycle user are related to its servicing. In case of car users, the repair costs are incomparably higher and, in addition to them, car owners also incur insurance and fuel costs. Much lower prices include the purchase of a train or a bus ticket, but the bicycle is still the most economical in financial terms.

Another important factor, for some, is travel time. Traffic in the city is unfortunately characterized by traffic jams, especially in the mornings and afternoons, so travelling by car or bus takes a very long time, which leads to frustration for drivers and passengers. Since all major cities are equipped with bicycle paths running along the pavement, travelling by bicycle helps significantly reduce travel time. Additionally, one can use various shortcuts by passing through places where traffic is not possible (e.g. squares, parks). When the streets are not congested, cycling time is slightly longer than by car. However, the lack of traffic jams in larger cities is a rare phenomenon.

The most characteristic feature of bicycle transport is its environmental friendliness. The only emissions released into the atmosphere arise during its production. It does not need fuel, so it does not lead to the need to extract or deplete any natural resources. It doesn't emit any pollutants without burning any fuel. Failure of this measure also does not threaten the environment in any way.

Failure rate is another feature that is worth considering. The bicycle does not break down very often, and the costs of removing the defect are relatively low. Inspections do not have to be carried out as often as in case of a motorbike or a car. It is also worth mentioning that, 
unlike a bus or a car, a breakdown does not reduce traffic flow, which in turn creates traffic jams.

The range of most means of transport is very large, however, only in terms of distance. As for urban transport, there are many places that can only be reached by bicycle or on foot. Of course, you can park your car in a different place and move on foot, but this is associated with longer time and discomfort. On the other hand, those travelling by bus are limited by the bus routes and quite rare distribution of bus stops (Corazza, 2019).

Parking is a problem that does not apply to cyclists. You can leave your bike practically anywhere, all you need is a bike lock. There are also many adapted places to leave the bike, every store or institution has stands to attach the bike.

Health and fitness aspects are an important element of cycling. Moderate physical effort promotes health and well-being (Raustorpa, 2019, Mertens, 2019). Regular cycling lowers the risk of heart, improves coordination and circulation in the veins, without stressing the joints (Štastná, 2018). More oxygen is also supplied, and you avoid stress related to driving and wasting time in traffic jams. On the other hand, cyclists on shared public roads have a greater risk of injury or death compared to those traveling by car (Nilssona, 2017). The risk of accident and injury largely depends on the condition of the bicycle infrastructure (Marshall, 2019).

However, you cannot hide that the downside is the ability to easily steal the bike. The loss of a car is undoubtedly much more expensive, but it happens much less often than a theft of bicycles.

Convenience is a questionable feature, depending on personal preferences (Thigpen, 2019). Some find it convenient to ride a bike in the fresh air, and some effort will be an advantage for them. However, late autumn and winter periods are certainly less comfortable for cycling than those in summer. Occurrence of rain significantly degrades comfort, while snowfall can even prevent driving. Such weather, however, does not bother bikers in Scandinavia (Böckera, 2019). Temperature and wind have the great impact on the rider, which is not the case for car drivers or bus passengers.

Another disadvantage is the inability to transport other people and larger loads. The need to make larger purchases excludes the option of using the bicycle as a means of transport.

To sum up, bicycle transport has some limitations related to weather conditions, the weight of transported cargo and the inability to take passengers. These restrictions also include the risk of theft. However, despite everything, it is undoubtedly the cheapest means of transport, both in terms of its purchase and a further operation. In many situations, bicycle transport is faster than car transport, especially in rush hour traffic. The bike allows reaching all places and parking problems are rare. Possible failures do not expose you to high costs and danger. Considering all the pros and cons, it can be stated that the bike is a means of transport cheap, economical, fast in the city, ecological and safe.

\section{EUROPEAN CYCLING LEADERS AND THEIR ACTIVITIES}

The development and popularization of cycling is influenced by many additional factors besides the benefits of cycling mentioned above. The most important factors include the condition and development of cycling infrastructure, the policy of city authorities favoring and promoting cycling, the construction and maintenance of city bike sharing networks, care for cycling safety and the promotion of a healthy lifestyle. In the latter case, it is both about the health and physical condition of society and about activities aimed at improving 
the condition of the urban environment by reducing air pollution. A large number of cities around the world are making efforts to restore the bicycle as an accepted and practical form of transport. Actions taken in these cities are registered and evaluated. On their basis, a ranking of friendly and supportive cities for cycling is created.

This ranking is known as the Copenhagenize Index. According to (https:// copenhagenizeindex.eu/) there are 15 European cities in the list of twenty most friendly and supporting bicycle transport in the world. In these fifteen, 14 cities the are cities of the old Union. The composition of the top three in six years has not changed. In 2015, Copenhagen took the first position and has maintained it up to this day. Fig. 1 shows the positions occupied by the first ten cities in the (https://copenhagenizeindex.eu/) ranking in 2017 and 2019.

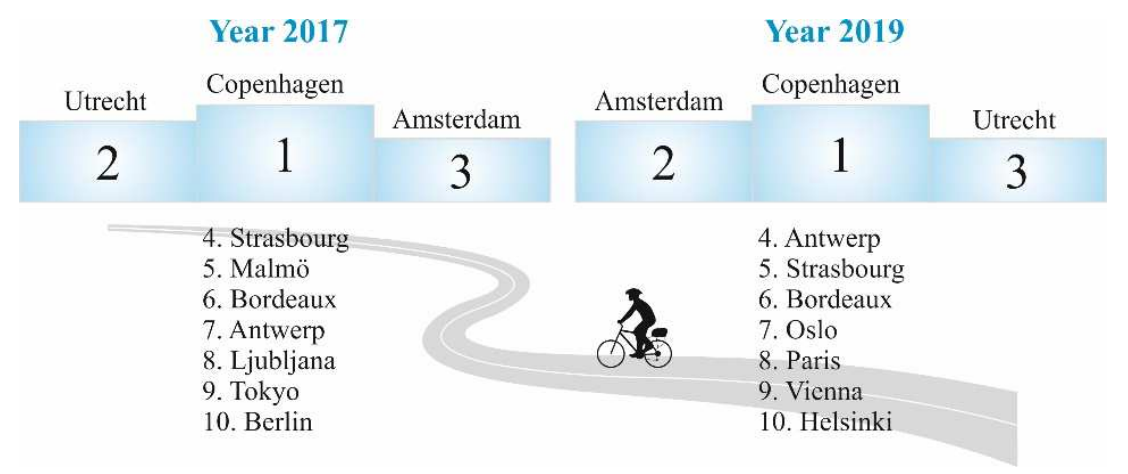

Fig. 1. Copenhagenize ranking of bicycle-friendly cities

Source: Prepared on the basis of (https://copenhagenizeindex.eu/).

Amsterdam and Copenhagen have been at the forefront of the ranking since its inception in 2011. In 2019, Copenhagen residents $62 \%$ travelled to work and school by bicycle. Every day they cover 1.44 million $\mathrm{km}$ by bike. City authorities are investing in cycling infrastructure. Calculated per capita, it is 40 euros per year. As part of the investments, 12 pedestrian and bicycle bridges were built, and $167 \mathrm{~km}$ of new regional bicycle highways were built. The new cycle paths in Copenhagen are 5.5 meters wide in every direction, which can accommodate 22,000 cyclists a day.

The second position in the ranking was won by the capital of the Netherlands, known worldwide for its cyclist-friendliness. The city is implementing a very ambitious cycling plan consisting in creating new cycling routes, expanding existing paths, building more cycling streets, redesigning major intersections to ensure safer cycling for cyclists. The plan is also predicted to be closed by 2025. 11,000 parking spaces for cars, which will be replaced by bicycle parking lots, greenery and walking places. The construction of a bicycle bridge is also planned. In Amsterdam, a ban on mopeds along cycling routes has also been introduced.

Utrecht is another Dutch city included in the ranking. It took 3rd place. Like many Dutch cities, Utrecht uses world-class cycling infrastructure. In Utrecht, bicycles are more important than cars. The city is building the world's largest bicycle parking structure, increasing the station's capacity to 22,000 bicycle parking spaces. 
The fourth place in the ranking is occupied by Belgian Antwerp. The bicycle transport development plan includes improving and connecting the bicycle network by enhancing intersections, managing traffic lights and striving to reduce car speed limits to $30 \mathrm{~km} / \mathrm{h}$ on $95 \%$ of all streets. Bicycle parking lots have also been expanded and bicycle highway networks connecting to the regions around the city are being expanded. Thanks to these investments, the share of bicycle transport in Antwerp increased from 29\% to 33\% in 2014-2018. The next stage of investment in bicycle transport will be the construction of a bicycle bridge.

Strasbourg was in the ranking after Antwerp. It is considered the most bike friendly city in France. The development of bicycle transport has been achieved thanks to the modernization of the road network and extension of bicycle highways. $16 \%$ of residents ride a bike to and from work or school. Bordeaux is another French city included in the ranking. Borodeaux maintains its position in the ranking because it continues to innovate and maintains the bike as a priority in transport planning in the city. Over the past two years, a ban on car traffic has been introduced on the historic Pont de pierre bridge, which has allowed a $20 \%$ increase in bicycle traffic and better conditions for walking or cycling.

The Norwegian capital city Oslo was seventh in the ranking. For the first time, Oslo was on the list of bicycle transport leaders in 2017, taking 19th place. Oslo should be an example for cities that claim that the climate or terrain prevents them from developing bicycle transport. Oslo's first investments and decisions were to remove cars from the city center and to eliminate 1000 parking spaces for cars. As a result, better conditions were created for residents moving by bicycle or on foot. Citizens and companies can benefit from subsidies for the purchase of bicycles for freight transportation. To enable residents to ride bicycles during the winter, which is not favorable for safe cycling, the city has equipped 400 bicycles with studded tires as part of a pilot project.

Paris is the next city in the ranking. Paris, thanks to the extension of the bicycle network, improved its position in the ranking compared to 2017 by 5 positions. In spite of the thriving city bike rental system, it managed to achieve a 5\% share of bicycle transport in his travels. The planned achievement of a 15\% share for 2020 seems unrealistic at present.

Another city is Vienna, which in spite of modest investments in cycling infrastructure, stands out from other cities thanks to innovative and constructive communication activities and policies. The city's ability to use the untapped potential of freight bicycles in city logistics and city life has made Vienna a leader in the field of cycling policy. For years citizens have been able to rent free bicycles. Recently, the direct grant program has facilitated the purchase of over 300 freight bikes for local Viennese companies. In Vienna, cycling infrastructure is developing at a steady pace. To meet demand, the city has installed 5,000 parking spaces for bicycles over the past two years. The last of the cities analyzed is Helsinki. Currently, the share of bicycle transport in the city is $11 \%$. Helsinki has over 1300 kilometers of cycling infrastructure and 20 kilometers of bicycle highways, and another 140 kilometers are planned.

\section{COMPARISON OF SELECTED CITIES OF THE UNION AND POLAND}

One of the publication's aims was to compare the functioning of bicycle transport in selected EU cities. The comparison was made for four groups of cities. In each group of the cities compared, there were two cities from EU countries with many years of experience and two cities from the group of countries admitted to the Union after 2005. The basic 
indicator deciding about the allocation to a given group was the size of the city. An additional factor determining the selection of the city was the degree of economic development of the country represented by the city. The chart in Fig. 2 presents the ratio of current GDP per capita income to the average value in the group of EU countries. The curves presented in the chart do not fully reflect the income in selected cities. Big cities are usually economic centers and per capita income is usually higher than the country's average income. However, it can be assumed that such a situation applies to similarly large cities from the old EU member states as well as newly admitted ones.

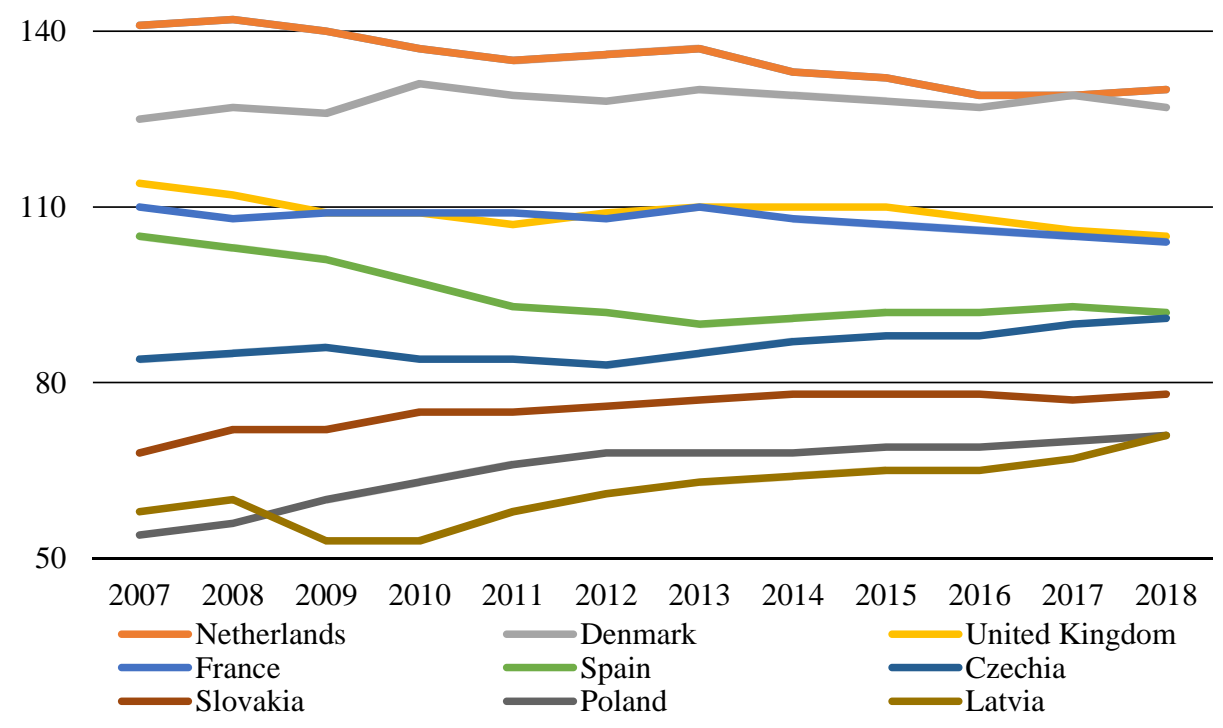

Fig. 2. Ratio of current GDP per capita income to the average value in the group of EU countries

Source: Prepared on the basis of (https://ec.europa.eu/).

The first compared group comprised the cities with over one million inhabitants (fig. 3). This group included four cities: Paris, Barcelona, Budapest and Warsaw. In all these cities, the use of bicycle transport according to splitmodal data ranges from $1 \%$ to $3 \%$. Such a negligible share of bicycle transport indicates that these are large agglomerations where bicycles are used primarily for recreational purposes. Due to the large distances that residents have to travel when going to work, most of them use other forms such as public transport (metro, public transport). However, these cities do not neglect efforts to develop bicycle transport. 


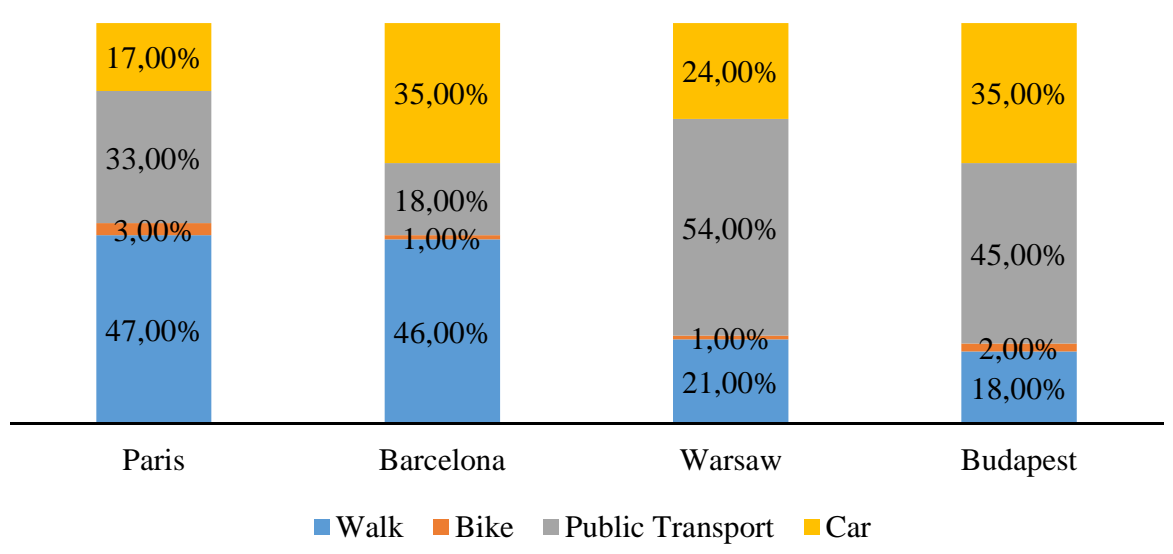

Fig. 3. Percentage distribution between different modes of transport in cities with more than 1 million inhabitants

Source: Prepared on the basis of (http://www.epomm.eu/)

The second group of cities analyzed were cities from 500,000 up to 1 million inhabitants (fig. 4). In this group, Amsterdam, Copenhagen, Wroclaw and Riga were analyzed. The first two of them are considered European leaders when it comes to using cycling. In the case of Amsterdam, the share of bicycle transport is 22\%, and Copenhagen $30 \%$.

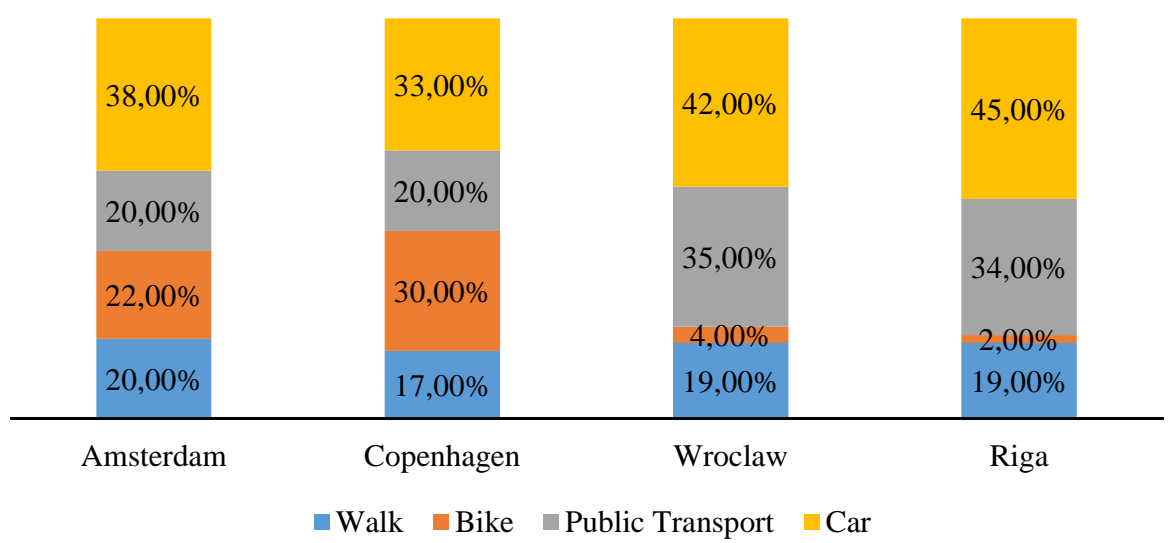

Fig. 4. Percentage distribution between different means of transport in cities with a population of 500,000 to 1 million

Source: Prepared on the basis of (http://www.epomm.eu/),

However, in the other two cities in this group the share of bicycle transport is marginal and amounts to $4 \%$ for Wroclaw and $2 \%$ for Riga, respectively. It is worth noting the income level of the inhabitants of the cities analyzed. In the case of the Netherlands (Amsterdam) 
and Denmark (Copenhagen) it ranged from $127-142 \%$ in relation to the average income per EU citizen in 2007-2018. However, in the case of Poland (Wroclaw) and Latvia (Riga) this income does not exceed $70 \%$ of the average income for a resident of the EU. There is a relationship here. Namely, in high-income countries, residents pay more attention to issues such as sustainable transport, and thus the economic benefits of implementing this idea and minimizing the environmental impact of vehicles.

The third group analyzed were the cities from 150,000 up to 250,000 residents (fig. 5). In this group four cities of Eindhoven, Oxford, Plzen and Gdynia were analyzed. Also in this group of cities one can notice significant differences in the use of bicycle transport depending on the economic development of a given country. In the case of Eindhoven (The Netherlands), the average income of the inhabitants of the Netherlands during the years 2007-2018 ranged from 130 to over 140\% of the average income of the Union, and the share of bicycle transport in this city accounts for $40 \%$. The residents of Oxford also boast a high use of bicycle transport - 19\%. The income of the inhabitants of England in the period analyzed ranged from 104 to $112 \%$ of EU income. The next two cities are characterized by very little use of bicycle transport. For Pilsen it is 3\%, while for Gdynia $2 \%$. In both the Czech Republic and Poland, the average per capita income is lower than the average EU per capita income. In the case of the Czech Republic, this income at the turn of 2007-2018 was in the range of 85-90\%. However, for Poland, this income does not exceed $70 \%$ of the average EU income. Also in this group of cities one can notice a greater awareness and care for the environment of residents of cities with a higher per capita income.

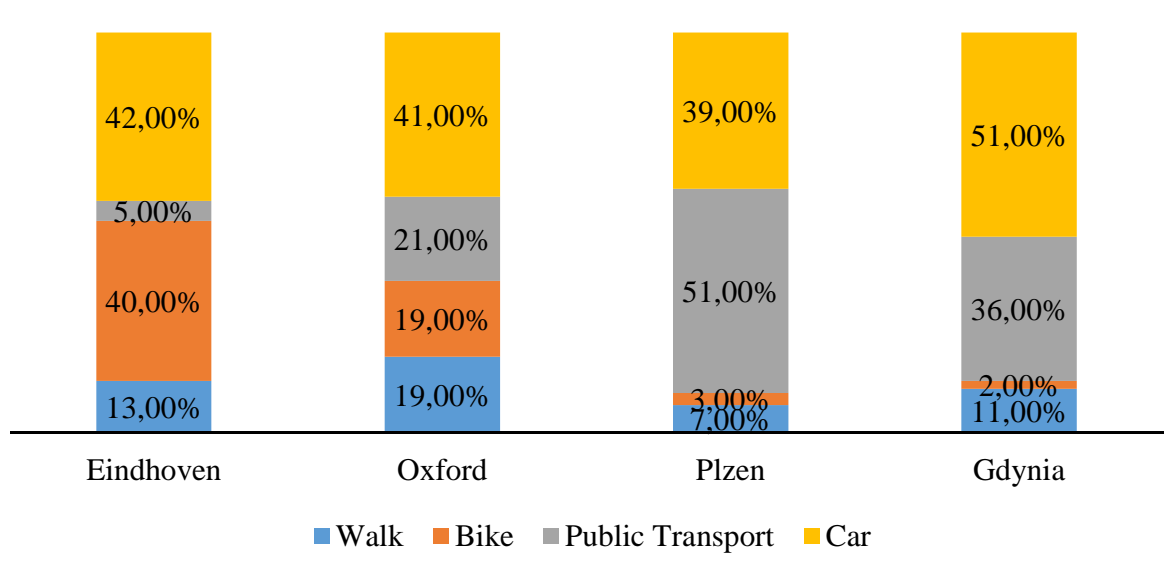

Fig. 5. Percentage distribution between different means of transport in cities with a population of 100,000 to 250,000

Source: Prepared on the basis of (http://www.epomm.eu/).

The last group of the cities analyzed were the ones of 50,000 up to 100,000 residents (fig. 6). As in the previous groups, four cities were analyzed. The first two cities are Delft (the Netherlands) and Gladsaxe (Denmark). For both the first and the second cities, the income of residents exceeds the average income per EU citizen, and the share of cycling is $34 \%$ (Delft) and 23\% (Gladsaxe), respectively. In the case of two further cities, the share of 
bicycle transport is $7 \%$ (Konin) and $8 \%$ (Zilina). Income in Slovakia does not exceed 80\% of the average income of EU residents. For Poland it is 10 points lower percentage and does not exceed $70 \%$.

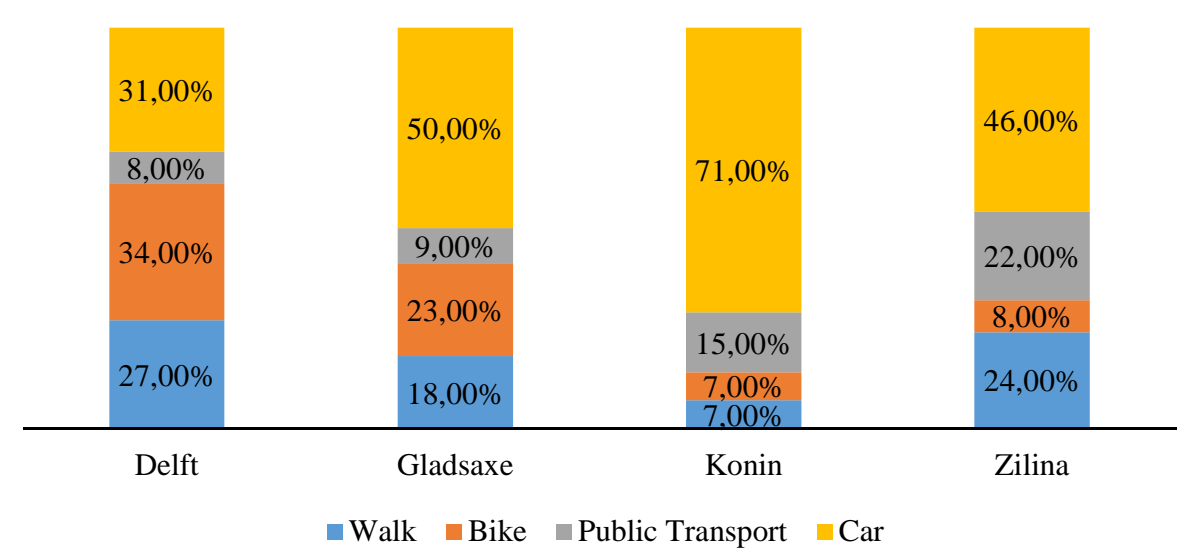

Fig. 6. Percentage distribution between different means of transport in cities with a population of 50,000 to 100,000

Source: Prepared on the basis of (http://www.epomm.eu/).

In the group of cities with a population of less than 1 million, there is a clear link between economic development and the share of cycling. The higher the income, the more developed bicycle transport is. In wealthier countries, the idea of sustainable transport is widespread. Hence, care for minimizing the harmful effects of vehicles on the environment and awareness of the economic benefits of implementing this idea. Large cities have a very well-developed public transport network based in most cases on the subway. Due to the large area of cities, one-off journeys are definitely longer and traffic on crowded streets is not very safe.

\section{THE CONDITION OF BICYCLE TRANSPORT IN POLAND}

The development of bicycle infrastructure is being observed throughout Poland. The increase in the share of bicycle transport in Poland and change of habits is slowly noticeable (Biernat 2018). Bicycle paths are created both in cities and along extra-urban routes. An increasing number of cities are also investing in city bike rentals. In 2018, there were $13,904.7 \mathrm{~km}$ of bicycle paths throughout Poland . Warsaw is the leader among Polish cities in terms of the length of bicycle paths. The length of bicycle paths in the capital is $590 \mathrm{~km}$ (fig. 7). As part of the municipal bicycle rental in Warsaw, cyclists have over 390 stations and over 5,700 bikes at their disposal. Wroclaw is the next largest bike path in terms of length. In 2018, it had $260 \mathrm{~km}$ of bicycle paths. Wroclaw bike rental has approximately 200 stations and 2,000 bikes. Poznan is equal to Wroclaw in terms of the length of bicycle paths, for which the length of bicycle paths is $242.5 \mathrm{~km}$. The Poznan bicycle system has 113 stations and about 1000 bikes. Cracow also invests in the bicycle transport system. It has 
bicycle routes with a length of $213.7 \mathrm{~km}$. The city bike system in Cracow offers 150 docking stations and about 1,500 bikes.

The advantages of cycling have been appreciated by Gdansk. The length of bicycle paths for Gdansk is $182.3 \mathrm{~km}$. In 2019, a system offering over 1,200 bikes and 660 parking stations operated in Gdansk and several other locations.

Another Polish city that appreciates the advantages of cycling is Lodz, which has 158.3 $\mathrm{km}$ of bicycle paths. The city bike system functioning in Lodz has 150 stations and over 1,500 bikes. The city of Rzeszow has a slightly smaller length of bicycle paths. It is 156.2 $\mathrm{km}$ of bicycle paths. The rental shop operating in Rzeszow offers 120 bicycles. Other Polish cities developing cycling infrastructure are: Lublin with $140 \mathrm{~km}$ of bicycle paths and a municipal bicycle rental of over 90 stations and 910 bicycles, Szczecin with $137.3 \mathrm{~km}$ of bicycle paths and a municipal bicycle rental of 87 stations and 742 bicycles, Bialystok with $128.4 \mathrm{~km}$ of bicycle paths and a municipal bicycle rental with 59 stations and 625 bicycles.

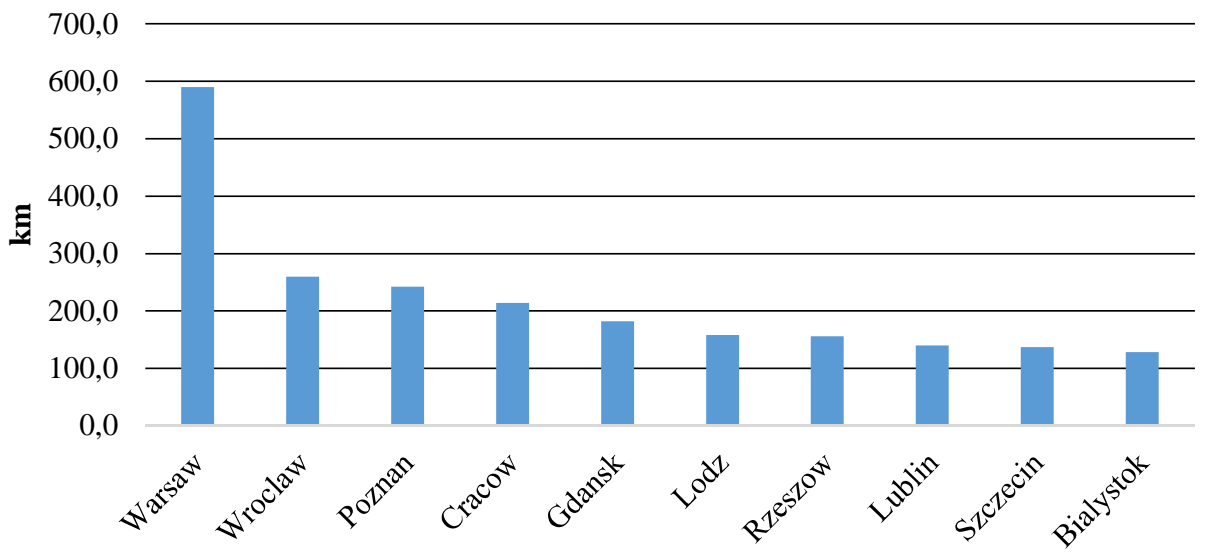

Fig. 7. Length of bicycle paths in selected Polish cities

Source: Prepared on the basis of (https://bdl.stat.gov.pl).

Many cities decide to implement urban cycling systems and develop cycling infrastructure not only because of the popularization of bicycles as one of the basic means of transport, but also because of the need to create modern interchanges. Bicycles are to increase the accessibility of integration nodes and enable faster and more comfortable transfers, e.g. to a train, bus, trolley bus or tram. Thanks to such solutions, the mobility of travelers increases and an alternative to car travel is created. And this in turn reduces the negative impact on the environment and reduces exhaust emissions and noise.

\section{CONCLUSION}

Inhabitants of many cities complain about the poor quality of life manifested in polluted air, high noise levels, accidents, and occupying more and more space by cars (Śmieszek 2016). Therefore, it is very important to make the public aware of the assumptions and benefits of introducing sustainable transport. One of its main assumptions is to limit the use 
of cars for environmentally friendly means of transport. A bicycle is one such ecological means of transport. Sustainable transport assumes the sharing of means of transport with an emphasis on the use of environmentally friendly ones, thus ensuring more economical management of financial resources and time as well as more effective protection of the natural environment. All these activities contribute to improving the quality of life of residents. As the analyzes carried out in the article showed, the inhabitants of highly developed countries, whose inhabitants can boast a high income exceeding the average income per EU citizen, were more aware of the beneficial effects of sustainable transport. The leaders in this group are residents of Denmark and the Netherlands. A very large $40 \%$ share of bicycle transport in public transport is observed in the cities of these two countries. The situation is worse in poorer countries where the average per capita income does not exceed $80 \%$ of the average EU per capita income. This group includes Poland. In these countries, the share of bicycle transport is very low and reaches several percent. It is optimistic that these countries draw examples from the more developed EU countries and strive to improve this situation by implementing a number of projects and projects aimed at implementing new, environmentally friendly means of transport which is definitely the bicycle

\section{REFERENCES}

Bagloee, S.A., Sarvi, M., Wallace, M. (2016). Bicycle lane priority: Promoting bicycle as a green mode even in congested urban area. "Transportation Research" Part A 87 (2016), ELSEVIER.

Biernat, E., Buchholtz, S., Bartkiewicz, P. (2018). Motivations and barriers to bicycle commuting: Lessons from Poland. "Transportation Research" Part F 55 (2018), ELSEVIER.

Böckera, L., Utengb, T.P., Liuc, Ch. Dijstd, M. (2019). Weather and daily mobility in international perspective: A crosscomparison of Dutch, Norwegian and Swedish city regions. “Transportation Research Part” D: Transport and Environment, Vol. 77, December 2019.

Corazza, M.V. Favaretto, N. (2019). A Methodology to Evaluate Accessibility to Bus Stops as a Contribution to Improve Sustainability in Urban Mobility. "Sustainability" 2019 11(3):803

Gutiérrez, M., Hurtubiab, R., de Dios Ortúzarc, J. (2020). The role of habit and the built environment in the willingness to commute by bicycle. "Travel Behaviour and Society" 20 (2020), ELSEVIER.

https://bdl.stat.gov.pl

http://www.epomm.eu

https://ec.europa.eu

https://copenhagenizeindex.eu

Kaltenbrunner, A. et al. (2010). Urban cycles and mobility patterns: Exploring and predicting trends in a bicycle-based public transport system. "Pervasive and Mobile Computing" 6 (2010), ELSEVIER.

Marshall, W.E., Ferenchak, N.N. (2019). Why cities with high bicycling rates are safer for all road users. "Journal of Transort \& Health” 13 (2019), ELSEVIER.

Mertens, L. et al. (2019). Individual, social, and physical environmental factors related to changes in walking and cycling for transport among older adults: A longitudinal study. "Health \& Place" 55 (2019), ELSEVIER. 
Nilssona, P., Stigsona, H., Ohlinb, M., Strandroth, J. (2017). Modelling the effect on injuries and fatalities when changing mode of transport from car to bicycle. "Accident Analysis and Prevention" 100 (2017). ELSEVIER.

Raustorpa, J., Koglinb, T. (2019). The potential for active commuting by bicycle and its possible effects on public health. "Journal of Transport \& Health" 13 (2019), ELSEVIER.

Smieszek, M., Dobrzanska, M., Dobrzanski, P. (2019). Rzeszow as a City Taking Steps Towards Developing Sustainable Public Transport. "Sustainability” 2019

Śmieszek, M., Dobrzańska, M., Dobrzański, P. (2016). Analiza zmian w transporcie publicznym Unii Europejskiej na przykładzie wybranych miast. „Humanities and Social Sciences” 2016, Vol. XXI, 23 (1/2016).

Štastná, M., Vaishar, A., Zapletalová, J., Ševelová, M. (2018). Cycling: A benefit for health or just a means of transport? Case study Brno (Czech Republic) and its surroundings. “Transportation Research" Part F 55 (2018), ELSEVIER.

Woods, R., Masthoff, J. (2017). A comparison of car driving, public transport and cycling experiences in three European cities. "Transportation Research" Part A 103 (2017), ELSEVIER.

Thigpen, C. et al. (2019). Who is ready to bicycle? Categorizing and mapping bicyclists with behavior change concepts. "Transport Policy" 82 (2019), ELSEVIER.

DOI: $10.7862 /$ rz.2020.hss.16

The text was submitted to the editorial office: April 2020.

The text was accepted for publication: June 2020. 